\title{
Memória de trabalho e desempenho em tarefas de L2
}

\author{
Ingrid Fontanini \\ Janaina Weissheimer \\ Joara Martin Bergsleithner \\ Magareth Perucci \\ Raquel D'Ely \\ Universidade Federal de Santa Catarina
}

\begin{abstract}
O presente artigo examina se a natureza da relação entre memória de trabalho e desempenho em tarefas de língua estrangeira (L2) é geral ou específica. Uma bateria de quatro testes de memória de trabalho em inglês e quatro tarefas de desempenho foi aplicada em doze estudantes universitários de nível elementar em inglês como L2. A análise mostrou uma correlação significativa entre a medida geral de memória de trabalho e as tarefas de leitura, sintaxe e produção oral. Quanto às tarefas de memória de trabalho específicas, a medida de amplitude de leitura correlacionou significativamente com a tarefa de sintaxe, e a medida de amplitude oral correlacionou tanto com as tarefas de produção oral, quanto com as de sintaxe. Os resultados do presente estudo sinalizam para uma natureza híbrida da relação entre memória de trabalho e desempenho em tarefas em L2.
\end{abstract}

This paper examines whether the nature of the relationship between working memory and the performance in L2 tasks is domain-free or task-specific. A set of four working memory tests in English and four L2 performance tasks was applied to twelve undergraduate beginner students of English as a second language. Correlational analyses showed significant correlation between the operation-word span test and the reading, syntactic and speaking tasks. As for the specific span tests, the reading span test correlated significantly with the syntactic task, and the speaking span test correlated both with the speech production task and the syntactic task. The results of the present study point to a hybrid nature of the relationship between working memory capacity and L2 task performance.

\section{Introdução}

O presente estudo tem dois objetivos: [1] examinar a relação entre capacidade de memória de trabalho (medida através de testes de 
amplitude de memória) e o desempenho em tarefas de L2 (medido por diversas tarefas, entre elas: compreensão oral, conhecimento sintático, produção oral e percepção fonológica); e [2] investigar a natureza da relação entre capacidade de memória de trabalho e desempenho em tarefas de L2, ou seja, se ela é geral ou específica à tarefa. Nesse sentido,duas propostas teóricas podem ser encontradas na literatura e evidências empíricas têm confirmado ambas. De um lado, Turner e Engle (1989), Engle, Kane e Tuholski (1999), entre outros, têm se manifestado a favor de uma hipótese de capacidade unitária, a qual considera a capacidade de memória de trabalho independente da natureza da tarefa proposta. De outro lado, Daneman e Carpenter (1980) trazem a visão de especificidade da capacidade de memória, enfatizando que a capacidade de um indivíduo varia de acordo com sua eficiência em relação aos processos específicos que são correlacionados com uma determinada tarefa.

É importante salientar que embora essas duas linhas de pesquisa tenham ambas trazido evidências para confirmar suas suposições, a questão sobre a natureza das diferenças individuais em memória de trabalho permanece sem solução (MIYAKE e SHAH, 1999; FORTKAMP, 2000). Por isso, o presente estudo visa contribuir com a discussão sobre ser a capacidade de memória de trabalho uma capacidade funcional e específica à tarefa, ou ser ela uma capacidade unitária que permeia o desempenho em qualquer tarefa.

Apesar de uma quantidade considerável de estudos ter sido realizada sobre o assunto memória de trabalho e desempenho em tarefas lingüísticas, nenhum estudo foi até hoje abrangente o suficiente para englobar uma certa gama de habilidades. A maior parte deles se restringe à compreensão de leitura (JUST e CARPENTER, 1980; KINTSCH e van DIJK, 1978; TOMITCH, 1996, entre outros) e apenas alguns abordam a produção oral (DANEMAN, 1991; FORTKAMP, 1999; FORTKAMP, 2000). Devido a essa lacuna na pesquisa, o presente estudo objetiva não só examinar a relação entre capacidade de memória de trabalho e desempenho em L2 nos domínios de leitura e produção oral, mas também em tarefas de sintaxe e fonologia como outros possíveis domínios a serem investigados. Nesse sentido, as seguintes perguntas de pesquisa são formuladas: 
- Existe uma correlação significativa entre a capacidade de memória geral, medida pelo teste de amplitude de memória operation-word, e tarefas em diferentes domínios de L2: compreensão de leitura, sintaxe, produção oral e percepção fonológica?

- Existe uma correlação significativa entre a capacidade de especificidade de memória de trabalho (medida pelo teste de amplitude de leitura, teste de amplitude de fala e teste de amplitude sintática) e as medidas de desempenho em tarefas em L2, nos domínios de compreensão de leitura, produção oral, percepção fonológica e sintaxe?

A partir dessas duas perguntas de pesquisa, as seguintes hipóteses foram geradas:

- Hipótese 1: A medida geral de memória de trabalho (obtida através do teste OSPAN) irá correlacionar com as medidas de desempenho em tarefas em L2 (compreensão de leitura, sintaxe, produção oral e percepção fonológica), apontando para uma natureza unitária da capacidade de memória de trabalho.

- Hipótese 2: As medidas de especificidade de capacidade de memória de trabalho (RSPAN, SSPAN, SYSPAN) irão correlacionar com suas respectivas tarefas em L2, ou seja, o RSPAN irá correlacionar com a medida de compreensão de leitura, o SSPAN irá correlacionar com a medida de produção oral e percepção fonológica e o SYSPAN irá correlacionar com a medida de conhecimento sintático. Caso isso se confirme, os resultados apontarão para uma natureza de especificidade da memória de trabalho.

Este artigo está organizado em quatro seções. Na primeira seção, discutimos o conceito de memória de trabalho a partir da sua ligação com a memória de curto prazo. Revisamos, também, o método psicométrico correlacional de análise de dados e abordamos, ainda, a relação entre memória de trabalho e diferenças entre indivíduos. $\mathrm{Na}$ segunda seção, revisamos estudos sobre o papel da memória de trabalho em compreensão de leitura, sintaxe, fonologia e produção oral em L2. O método, os materiais e as tarefas utilizados neste experimento são apresentados na terceira seção, seguidos da análise de dados e discussão dos resultados obtidos. Finalmente, na quarta seção, traçamos 
algumas considerações finais sobre as limitações deste estudo e sugerimos, ainda, diretrizes para futuras investigações.

\section{Revisão de literatura}

\section{Perspectivas em memória de curto prazo e memória de trabalho}

A psicologia experimental tem dedicado décadas investigando e procurando explicar o papel da memória de curto prazo na cognição humana. Inicialmente, a memória de curto prazo era considerada um sistema unitário passivo, com limitada capacidade para processar e armazenar informações (ASHCRAFT, 1994; BADDELEY, 1990; ENGLE e ORANSKY, 1999; TOMITCH, 1995, entre tantos outros). Seguindo essa linha de pensamento, um dos modelos mais citados na literatura sobre cognição é o modelo de três estágios de Atkinson e Shiffrin (1968). De acordo com esse modelo, a informação, em um estágio inicial, deveria passar simultaneamente por diferentes sensores chamados "buffers", e através do processo da reciclagem (repetição), essa informação passaria para a memória de longo prazo. Dessa maneira, o volume de informações armazenadas estaria diretamente ligado ao total da reciclagem. Essa visão foi considerada problemática por duas razões: (a) ela não explicava como pacientes com deficiência na memória de curto prazo podiam apresentar intacto o armazenamento de informações na memória de longo prazo; (b) estudos demonstraram que a repetição não necessariamente leva ao aprendizado (TULVING, 1966). Em outras palavras, a repetição realizada pela memória de curto prazo nem sempre resulta em um armazenamento eficaz na memória de longo prazo. Conseqüentemente, o modelo proposto por Atkinson e Shiffrin (1968), que considerava a memória de curto prazo como sendo constituída por apenas um sistema, passou a ser questionado e posteriormente foi abandonado.

$\mathrm{Na}$ evolução dos modelos cognitivos, uma das visões mais influentes foi desenvolvida por Baddeley e Hitch (1974). Segundo estes pesquisadores, a memória de curto prazo teria não só a função de armazenar informações, mas agiria também como uma "memória de trabalho". Segundo Baddeley (1992), memória de trabalho é um sistema cerebral responsável pela manipulação e armazenamento de 
informações necessárias para a execução de tarefas cognitivas complexas, tais como a compreensão da linguagem, a aprendizagem e o raciocínio. O modelo de memória de Baddeley e Hitch (1974) foi particularmente influente pelo fato de propor um sistema que passou a ser designado de memória de trabalho, o qual era constituído por diferentes subsistemas que poderiam explicar certos fenômenos cognitivos até então questionados.

Entretanto, no campo da psicologia cognitiva ainda nos defrontamos com controvérsias envolvendo a relação entre memória de trabalho e memória de curto prazo. Sendo assim, ao mesmo tempo em que alguns pesquisadores declaram que a memória de curto prazo possui conceito similar ao da memória de trabalho (ANDERSON, 1990), outros afirmam que memória de trabalho é um sistema mais complexo, sendo vista como "o conjunto de elementos ativos da memória" (COWAN, 1995, p. 100. Tradução das autoras). No entanto, apesar das polêmicas apresentadas, teorias mais recentes definem a memória de curto prazo como um sistema mais dinâmico, capaz de armazenar e processar informações (JUST e CAPENTER, 1992; CANTOR e ENGLE, 1993; TOMITCH, 1996). A diferença entre memória de curto prazo e memória de trabalho residiria no seguinte fato: enquanto a memória de curto prazo apresenta suas limitações no número de itens armazenados, a memória de trabalho apresenta suas limitações no número de recursos atencionais disponíveis para o processamento das informações (TOMITCH, 1996; JUST e CARPENTER, 1992).

\section{O paradigma Psicométrico-Correlacional}

Segundo Baddeley (1992), as pesquisas em memória de trabalho se desenvolveram em duas correntes consideradas complementares: $\mathrm{O}$ modelo de duas tarefas e o psicométrico. O primeiro, conforme o nome sugere, consiste da aplicação de duas tarefas - por exemplo, lembrar de uma lista de números e ao mesmo tempo processar certas informações (BADDELEY, 1990). Nesse tipo de atividade tenta-se observar e explicar a estrutura da memória de trabalho. O segundo enfoque, psicométrico, está interessado na investigação da relação entre a capacidade da memória de trabalho e o desempenho em atividades cognitivas propostas, já que esses estudos demonstram haver uma 
grande correlação entre ambos (DANEMAN e CARPENTER, 1980; ENGLE, KANE e TUHOLSKI, 1999, entre outros).

O presente trabalho foi conduzido dentro do enfoque psicométrico na tentativa de observar a relação entre a memória de trabalho e as atividades de leitura/compreensão em L2, competência sintática, produção da fala e percepção fonológica.

\section{Diferenças individuais na memória de trabalho}

Como foi visto anteriormente, o enfoque psicométrico correlacional estabelece que há uma relação entre a memória de trabalho e a performance em atividades cognitivas complexas, tais como: (a) compreensão da leitura (TOMITCH, 1996; JUST e CARPENTER, 1980; KINTSCH e van DIJK, 1978); (b) compreensão da leitura em L2 (HARRINGTON, 1992; BERQUIST, 1998); (c) habilidade de abstrair regularidades gramaticais tanto em L1 como em L2 (ELLIS e SINCLAIR, 1996; MIYAKE e FRIEDMAN, 1998); (d) produção da fala em L2 (FORTKAMP, 2000). Além disso, segundo este enfoque, indivíduos com maior capacidade de memória de trabalho seriam mais aptos a desenvolver determinadas atividades propostas. Esse fato tem sido demonstrado por uma série de estudos (ENGLE, KANE e TUHOLSKI, 1999; JUST e CARPENTER, 1980, 1992, entre outros).

No entanto, como dito anteriormente, o que permanece controverso na literatura é se a relação entre memória de trabalho e certos aspectos cognitivos é de livre domínio ou específica a determinadas atividades. Sendo assim, enquanto pesquisadores adeptos à visão de capacidade de memória de trabalho funcional (DANEMAN e CARPENTER, 1980) afirmam que a capacidade de memória de trabalho varia de acordo com a eficiência individual do processamento em uma determinada atividade, outros pesquisadores encontram evidências que corroboram a hipótese da capacidade geral da memória de trabalho, ou seja, a capacidade como sendo independente da natureza da atividade proposta (TURNER e ENGLE, 1989; ENGLE, KANE e TUHOLSKI, 1999). 


\section{Memória de trabalho e desempenho em tarefas}

\section{Memória de trabalho e compreensão da leitura}

Conforme argumentado até então, os testes de amplitude da memória de trabalho medem a capacidade de um indivíduo em armazenar informações que serão usadas em futuros processamentos. Comparações feitas entre os resultados obtidos pelos participantes nos testes de memória de trabalho e certas tarefas propostas apresentaram os seguintes resultados: (a) houve uma correlação significante entre o teste envolvendo soma-palavra (OSPAN) e a tarefa de compreensão de leitura $\left(.614^{*}\right)$. Esse resultado poderia ser um indicativo de que os participantes com maiores amplitudes de memória podem controlar melhor a alocação dos recursos necessários para o processamento das informações. Tal fato facilitaria a tarefa de armazenar e extrair as informações necessárias, tornando o processo mais rápido e preciso, o que poderia vir a minimizar a ocorrência de erros; (b) uma correlação significante também foi observada entre os testes de amplitude de memória em leitura e as tarefas de sintaxe (-.667*), medida obtida pelo número de erros apresentados. Este resultado pode corroborar o seguinte aspecto: as dificuldades sintáticas, fator que pode sobrecarregar a memória de trabalho na hora do processamento, foram menos cruciais para os participantes com maiores amplitudes de memória (JUST e CARPENTER, 1987), tornando a realização das tarefas mais fácil para os mesmos. Esse fato pode, além disso, indicar que os participantes com maiores amplitudes de memória de trabalho também poderiam possuir competências lingüísticas implícitas maiores, o que por sua vez também levaria a uma menor incidência dos erros. Competência lingüística implícita envolve o conhecimento de fonologia, morfologia, sintaxe e de aspectos semânticos da língua (PARADIS, 2000).

Enquanto os aspectos anteriormente relatados confirmam as hipóteses encontradas na literatura sobre memória de trabalho, surpreendentemente apenas uma baixa correlação foi encontrada entre os testes de amplitude de memória em leitura e as tarefas de compreensão de leitura. Uma possível explicação para tal resultado é que o texto usado para a leitura subestimou o nível de inglês dos participantes que, embora fossem iniciantes, tinham um nível de conhecimento acima do esperado. Sendo assim, as tarefas exigidas deixaram de ser complexas, 
não apresentando dificuldade de processamento nem mesmo para os participantes com baixa amplitude de memória, possibilitando-lhes executar as tarefas estratégica e habilmente. Levando-se em consideração que possíveis diferenças entre participantes com baixa/alta amplitude de memória são mais claramente observadas em tarefas que impõem um peso maior no processamento (MIYAKE e FRIEDMAN, 1998), uma vez que tal peso tenha deixado de existir, o resultado obtido passaria a ser justificado. Entretanto, mais investigações (com os mesmos participantes) deveriam ser conduzidas para que possíveis resultados pudessem ser ampliados e confirmados (ou não), proporcionando uma base mais sólida para a interpretação dos mesmos, principalmente levando-se em consideração que "os resultados correlacionais por si só possuem pouco valor explanatório" (HARRINGTON, 1992, p. 124). Além do mais, devido ao fato de que esse estudo é de natureza correlacional e não experimental, os resultados também são susceptíveis a interpretações causais e não axiomáticas. Entretanto, apesar das limitações inerentes a essa investigação, os dados correlacionais obtidos parecem oferecer um caminho importante para a investigação das dimensões na variação em proficiência de L2 (MIYAKE e FRIEDMAN, 1998).

\section{Memória de trabalho e produção oral}

Esta breve revisão de literatura tem dois objetivos: (1) revisar alguns estudos que investigaram a capacidade de memória de trabalho como um indicativo da fluência oral em L1 e L2, e (2) revisar alguns estudos empíricos na área de produção oral em L2.

Tendo a memória de trabalho um papel decisivo no desempenho de tarefas cognitivas complexas, como é o caso da habilidade da fala tanto em L1 quanto em L2 (veja LEVELT, 1989; GREEN, 1996; MYAKE e SHAH, 1999, por exemplo), tentativas têm sido feitas para investigar se a capacidade de memória de trabalho pode ser responsável por diferenças individuais na fluência verbal dos indivíduos (DANEMAN, 1991; FORTKAMP, 1999, 2000, entre outros).

Daneman (1991) examinou se a capacidade de memória de trabalho correlacionava com o desempenho de fluência em L1 numa população de 29 falantes nativos de Inglês. As medidas de memória de trabalho foram acessadas por um teste de amplitude de memória de 
trabalho na habilidade da fala (escores estrito e leniente) e um teste de amplitude de memória de trabalho em leitura. A fluência verbal foi avaliada em três tarefas: (1) tarefa de produção oral, (2) tarefa de leitura em voz alta e (3) tarefa de slip of the tongue. Resultados gerais sugeriram que houve uma correlação significante entre a amplitude de memória de trabalho na habilidade oral e o desempenho nas três tarefas propostas. No entanto, a amplitude de memória de trabalho na habilidade de leitura correlacionou somente com a tarefa de leitura em voz alta. Essas descobertas indicam que a memória de trabalho não é um sistema geral; ao contrário, pode variar "como função de quão eficiente o indivíduo é num processo específico exigido pelas tarefas às quais a memória de trabalho está sendo aplicada" (DANEMAN, 1991, p. 461. Tradução das autoras).

Fortkamp (1999), adaptando o estudo de Daneman (1991), investigou a correlação entre capacidade de memória de trabalho e produção oral fluente em língua estrangeira numa população de 16 falantes avançados de inglês. Testes de amplitude de memória de trabalho foram conduzidos em português em inglês, e os participantes atuaram nas mesmas três tarefas realizadas no estudo de Daneman (1991). Resultados gerais sugerem que houve uma correlação significante entre o teste de amplitude de memória de trabalho na habilidade da fala em inglês e as tarefas de produção oral. O teste de amplitude de memória de trabalho na habilidade da leitura, em português e em inglês, correlacionou de maneira significante com a tarefa de leitura em voz alta. Dessa maneira os resultados corroboram a visão de que a capacidade de memória de trabalho parece ser específica à tarefa realizada.

Objetivando questionar de maneira mais compreensiva a relação entre memória de trabalho e produção oral em L2, Fortkamp (2000) investigou essa relação numa população de 13 aprendizes avançados de inglês como L2. A capacidade de memória de trabalho dos participantes foi medida por um teste de memória de trabalho na habilidade da fala e também por um teste operation-word, cujas versões foram as mesmas utilizadas em Fortkamp (1999). Os participantes atuaram em duas tarefas orais: uma descrição e uma tarefa narrativa, com o propósito de extrair produção oral em L2, que foi medida em termos de fluência, precisão, complexidade e densidade lexical. Os 
resultados indicaram que participantes que têm uma capacidade de memória de trabalho mais ampla atuam oralmente de modo mais rápido, utilizam com menor freqüência pausas silenciosas e produzem fala mais complexa e gramaticalmente mais correta do que aqueles que têm menor capacidade de memória de trabalho. No entanto, o desempenho oral fluente, complexo e gramaticalmente correto dos participantes foi conseguido às custas de uma fala que é mais hesitante e lexicalmente menos densa. Em termos gerais, nessa pesquisa, o teste de amplitude de memória de trabalho na habilidade da fala mostrou ser um determinante confiável de desempenho fluente, complexo e gramaticalmente correto em L2, porém não houve evidência empírica suficiente para discutir se a capacidade de memória de trabalho é específica à tarefa ou de domínio amplo. Contudo, os resultados parecem tentativamente sugerir que pode haver "uma relação linear entre capacidade de memória de trabalho e produção oral em L2" (FORTKAMP, 2002, p. 149. Tradução das autoras).

Finalizada a breve revisão de literatura abrangendo alguns estudos empíricos sobre a relação entre capacidade de memória de trabalho e desempenho oral, revelando uma tendência a aceitar a visão de que a capacidade de memória de trabalho é específica à tarefa e também determina desempenho fluente, complexo e gramaticalmente correto, focaremos em alguns estudos empíricos na área de produção oral em L2.

A proposta do enfoque embasado em tarefas, tanto para a análise quanto para a implementação das mesmas (SKEHAN, 1998), parte do pressuposto de que fatores psicológicos e condições de processamento são altamente relevantes para a aprendizagem de L2. Duas questões centrais surgem nessa perspectiva pedagógica (SKEHAN, 1996): (1) atenção e noticing são centrais para o desenvolvimento do processo de aprendizagem (SCHMIDT, 1990); e (2) recursos atencionais são limitados (Van PATTEN, 1990). Conseqüentemente, deve haver maneiras nas quais tal atenção possa ser manipulada para que haja um equilíbrio entre os objetivos que competem entre si no ato da fala - fluência, precisão e complexidade. É então com o objetivo de focar em maneiras usadas pelos aprendizes para manipular as condições de fala que a questão de tempo para planejar (planejamento estratégico) tem sido extensivamente pesquisada na área da aquisição de segunda língua. 
Em relação ao desempenho dos aprendizes em L2, vários estudos foram conduzidos com o propósito de investigarem-se os efeitos de planejamento estratégico para incrementar o desempenho oral dos aprendizes (ELLIS, 1987; CROOKES, 1989, ORTEGA, 1999; MEHNERT, 1998; FOSTER e SKEHAN 1996; SKEHAN e FOSTER, 1995; WIGGLESWORTH, 2001, por exemplo). Resultados desses estudos trazem evidência para o fato de que o planejamento estratégico tem efeitos benéficos no desempenho oral em L2 e que, portanto, deveria ser visto como uma condição para a atuação em tarefas orais. De maneira geral, os resultados também sugerem que a complexidade é o aspecto do desempenho mais aberto a ganhos; e parece haver também evidência para dar suporte à visão de que os recursos atencionais dos falantes são limitados. Sendo assim, existem 'efeitos desbalanceados' (trade-offs) entre os três objetivos que competem entre si no ato da fala: fluência, complexidade e precisão. Além disso, os resultados apontam para ganhos na fluência e complexidade, que ocorrem em detrimento da precisão. Outrossim, parece haver uma relação intrínseca entre tipo de tarefa, características da tarefa, condições da tarefa e o modo como os aprendizes encaram a condição de planejamento estratégico.

Essa breve revisão de literatura ratifica a relação linear que existe entre memória de trabalho e atuação fluente, complexa e gramaticalmente correta em L2 e também aponta para a complexidade que existe em tentativas de se otimizar a produção oral em L2. Portanto, parece ser importante a busca por respostas que venham elucidar a natureza da relação entre a capacidade de memória de trabalho e a produção oral em L2.

\section{Memória de trabalho e sintaxe}

A pesquisa sobre diferenças individuais em memória de trabalho tem focado principalmente em leitura e produção oral em L2. Entretanto, algumas contribuições importantes têm surgido sobre a relação entre memória de trabalho e sintaxe, principalmente na área de aquisição de língua estrangeira.

A abstração e aplicação de regras em L2 é uma tarefa cognitiva altamente complexa, uma vez que uma quantidade enorme de atenção deve ser alocada à supressão do sistema lingüístico da língua materna (ELLIS e SINCLAIR, 1996), ao mesmo tempo que se computa a 
informação sintática de palavras, frases e orações sucessivas na L2 (JUST e CARPENTER, 1987).

Ellis e Sinclair (1996) apontam para um papel significativo da memória de trabalho na aquisição de sintaxe em L2, alegando que indivíduos que possuem déficit em memória de trabalho apresentam uma restrita aquisição de sintaxe tanto na língua materna quanto em L2. Em um estudo realizado por esses pesquisadores, indivíduos que não puderam repetir frases em L2 durante o teste de memória de trabalho foram menos capazes de usar conhecimento metacognitivo sobre regras sintáticas para abstrair regularidades gramaticais de sentenças e ficaram, portanto, mais sujeitos a produzir erros.

Semelhantemente, Harrington e Sawyer (1992) mostraram, através de correlações, que leitores com alta capacidade de memória de trabalho em leitura se destacaram nas seções de gramática e vocabulário do TOEFL (Test of English as a Foreign Language), corroborando a idéia de que, pelo menos até certo ponto, a relação entre memória de trabalho e compreensão de leitura em L2 é mediada por conhecimento gramatical e lexical na L2.

Outro estudo (MIYAKE e FRIEDMAN, 1998) também indica que a relação entre memória de trabalho e conhecimento gramatical em L2 é direta. Após comparar preferências em termos de ordem de palavras entre japoneses estudantes de inglês e falantes nativos de inglês e, ainda, levando em conta a amplitude de memória de trabalho desses estudantes, os pesquisadores mostraram que diferenças entre as memórias de trabalho dos participantes estavam sistematicamente relacionadas às suas preferências quanto à ordem de palavras, e que ambas influenciavam como os participantes interpretavam frases complexas em inglês. Usando uma ferramenta estatística mais sofisticada - path analysis - Miyake e Friedman desenvolveram um modelo capaz de mostrar como a memória de trabalho influencia a compreensão sintática em L2. Esse modelo, cuja contribuição para os estudos em sintaxe em L2 é memorável, representa a memória de trabalho como determinante da compreensão sintática em L2.

Mais recentemente, Fortkamp (2000) examinou a relação entre memória de trabalho e produção oral em L2, considerando a precisão gramatical uma possível variável. Ela obteve uma correlação negativa entre medidas de memória de trabalho e número de erros na produção 
oral em L2, indicando que participantes com maior capacidade de memória de trabalho eram também os que produziam menos erros. Com base nesses resultados, a pesquisadora concluiu que a memória de trabalho dos indivíduos é capaz de predizer seu desempenho sintático oral em L2.

Os estudos acima revisados contribuíram para elucidar o papel da memória de trabalho na aquisição, compreensão e uso de conhecimento sintático em L2. O presente estudo tem como objetivo contribuir para essa discussão.

\section{Memória de trabalho e fonologia}

Pesquisas de peso relacionando memória de trabalho e fonologia em L2 são praticamente inexistentes. Dentre os poucos pesquisadores que fizeram alguma observação sobre a relação entre memória de trabalho e fonologia de L2 está Baptista (1995), que advoga a importância de se ensinar pronúncia nas aulas de L2, afirmando que os processos fonológicos de percepção e produção fazem parte do conhecimento procedimental, e que ter os processos fonéticos e fonológicos automatizados é de extrema importância. Tal afirmação se comprova quando consideramos tarefas de percepção e produção de fala. Quanto mais automatizado estiver o sistema fonológico, mais fácil será para o falante/ouvinte realizar as tarefas de percepção e produção de fala em L2, uma vez que tais habilidades demandam um acesso contínuo da memória de trabalho. Para este trabalho a relação entre memória de trabalho e fonologia irá se ater à área de percepção da fala, deixando para um estudo futuro a relação entre memória de trabalho, fonologia e produção de fala, certamente não menos importante que a primeira.

Estabelecido o foco de memória de trabalho dentro de percepção de fala e fonologia, mister se faz trazer para este trabalho dois modelos importantes da percepção de fala. Escudero (2002) mostra a influência destes dois modelos essenciais para o entendimento da percepção da fala: (1) o SLM (Speech Language Model), também conhecido como modelo de Flege; e (2) o PAM (Perceptual Assimilation Model), também conhecido como modelo de Best. O SLM é "um modelo mentalista, no qual sons específicos de uma língua são representados na memória de longo prazo [...]. O modelo sugere que os sons da língua-alvo que 
encontram correspondentes em diferentes sons da L1 serão percebidos completamente da mesma forma que os falantes nativos os percebem" (ESCUDERO, 2002, p.122. Tradução das autoras). O segundo modelo parte do princípio de que

novos sons serão assimilados, de um modo ou de outro, às categorias já existentes na L1 dos falantes [...]. Com relação às questões de aprendizagem, o PAM prevê os graus de discriminação, mas não os processos envolvidos na aquisição de tal discriminação ((ESCUDERO, 2002, p.123).

Embora de suma importância para um melhor entendimento de como ocorrem os processos de percepção da fala em L2, tais modelos só fazem referência à memória de longa duração no que tange ao local onde os sons são representados. Há uma carência de estudos que investiguem memória de trabalho e fonologia de L2, os quais poderão trazer perspectivas para um melhor entendimento sobre o modo como os sons são percebidos por aprendentes de uma L2 enquanto realizam tarefas de percepção de fala. Tais estudos beneficiarão também ensinantes de L2, uma vez que poderão direcioná-los com relação aos cuidados que devem ter quando da elaboração de tarefas relacionadas ao ensino de fonologia de L2.

Esta pesquisa teria se beneficiado de estudos mais embasados relacionando memória de trabalho e fonologia de L2, uma vez que tais estudos poderiam ter fomentado idéias para a aplicação da tarefa relacionando fonologia e memória de trabalho, a qual será descrita em detalhes no item $A$ tarefa de percepçãofonológica da seção a seguir. É na tentativa de contribuir para um estreitamento na distância existente entre as questões teóricas e empíricas dessa área que este estudo foi conduzido.

\section{Método}

\section{Participantes}

Doze estudantes universitários de uma universidade brasileira participaram deste estudo: 7 mulheres e 5 homens, com idades entre 17 e 39 e uma média de 28 anos. Uma amostra, assim, relativamente jovem. Todos os participantes cursavam o segundo semestre do curso 
de Letras, podendo ser considerado, portanto, um grupo relativamente homogêneo em termos de proficiência em L2, proficiência essa suficiente para permitir que usassem o inglês razoavelmente bem para fins acadêmicos, incluindo a escrita e a fala.

\section{Tarefas e Procedimentos}

A coleta de dados foi dividida em duas fases: dia 1 e dia 2 . No primeiro dia, os participantes realizaram quatro testes de memória de trabalho individualmente. Nesses quatro testes (operation-wordOSPAN; reading span-RSPAN; speaking span-SSPAN, e syntactic span - SYSPAN), os participantes realizaram uma dupla-tarefa - dual-task, (BADDELEY, 1990) que consistia em sustentar na memória seqüências de palavras enquanto faziam uma tarefa de raciocínio, compreensão ou produção. Com o intuito de evitar efeitos de ordem das tarefas durante essa fase, os participantes foram divididos em quatro grupos, os quais foram submetidos aos testes de memória de trabalho em salas diferentes, na seguinte ordem:

\begin{tabular}{|l|c|c|c|c|}
\hline & OSPAN & SSPAN & RSPAN & SYNSPAN \\
\hline GRUPO 1 & 1 & 3 & 4 & 2 \\
\hline GRUPO 2 & 4 & 1 & 2 & 3 \\
\hline GRUPO 3 & 3 & 2 & 1 & 4 \\
\hline GRUPO 4 & 2 & 4 & 3 & 1 \\
\hline
\end{tabular}

TABELA 1 - Controle de ordem dos testes de memória

No segundo dia, os participantes realizaram as tarefas de habilidade em inglês. As tarefas em L2 eram compostas de uma tarefa de compreensão de leitura, uma narração de seqüência (tarefa de conhecimento sintático), um teste de discriminação de som (tarefa de percepção fonológica) e uma descrição de gravura (tarefa de produção oral). Todas as tarefas foram realizadas individualmente.

Durante o primeiro dia da coleta, as salas utilizadas pelos pesquisadores tinham um computador, um gravador e algumas cadeiras. No segundo dia, não foi necessária a utilização de um computador, então os participantes foram levados ao laboratório de 
línguas, onde cada um tinha um gravador, um microfone e fones de ouvido para realizarem as tarefas. As instruções para todos os testes e tarefas foram feitas na língua materna dos aprendizes - português - e foi permitido que eles fizessem perguntas até se sentirem confortáveis para começarem a realizar as tarefas. Além disso, os participantes foram informados de que os testes de memória exigiam muita concentração no estímulo para que um bom desempenho fosse alcançado.

Todos os testes e tarefas serão descritos na próxima seção. Entretanto, antes disso uma importante consideração deve ser feita. Ao realizarem os testes de memória em L2, os participantes foram expostos a uma carga cognitiva maior (ELLIS e SINCLAIR, 1996), em termos de habilidades sensoriais e motoras, do que aquela a que teriam sido expostos se tivessem realizado os testes em sua língua materna. Portanto, qualquer análise ou comparação entre estudos deve levar esse importante aspecto em consideração.

\section{Medidas de Capacidade de Memória}

\section{O teste operation-word (OSPAN)}

Baseado em Turner e Engle (1989), o teste de memória operationword foi elaborado com 60 seqüências matemáticas e 60 palavras em inglês. Cada seqüência matemática era acompanhada por uma palavra de uma ou duas sílabas à sua direita e apresentada uma de cada vez no meio da tela do computador, como mostra o exemplo abaixo:

$$
\begin{aligned}
& 3+5=? \text { house } \\
& 2+4=\text { ? beach }
\end{aligned}
$$

As 60 combinações de seqüências matemáticas e palavras em inglês foram organizadas em três grupos, sendo que cada um continha progressivamente duas, três, quatro, cinco e seis seqüências. As respostas às seqüências matemáticas eram dadas oralmente pelos participantes, ao mesmo tempo em que tinham que lembrar a palavra em inglês que acompanhava a seqüência. Esse procedimento foi mantido até que uma tela em branco sinalizasse que aquele grupo tinha acabado. Então, os participantes tinham que lembrar das palavras na ordem e forma em que elas haviam sido apresentadas. Todo esse procedimento foi 
gravado em uma fita cassete. Assim como nos estudos de Turner e Engle (1989), a cada participante foi dada a oportunidade de praticar e o teste só começou quanto o participante se mostrou confortável. Como em Engle, Cantor e Carullo (1992), a amplitude de operation-word de cada participante foi medida pelo número total de palavras que ele conseguiu lembrar, perfazendo um máximo de 60 palavras neste estudo.

\section{O teste de amplitude de leitura (RSPAN)}

Partindo do modelo original (DANEMAN e CARPENTER, 1980), o teste de amplitude de leitura neste estudo fez com que os participantes usassem ambas as funções da memória de trabalho durante a compreensão de leitura: o componente de processamento era a compreensão da frase, enquanto o componente de armazenamento era a manutenção e resgate da palavra final de cada frase de um conjunto apresentado.

O teste de amplitude de leitura era composto de 60 frases do tipo verdadeiro ou falso. Cada frase aparecia de uma vez no meio da tela do computador, como no exemplo abaixo:

\section{Rap is music \\ Japan is far}

As 60 frases foram organizadas em grupos de três, cada qual progressivamente com duas, três, quatro, cinco e seis frases, como no teste operation-word acima descrito. Os participantes leram as frases em voz alta, respondendo imediatamente se eram verdadeiras ou falsas. Uma tela em branco sinalizava que os participantes deveriam lembrar das palavras finais de cada frase na ordem que elas tinham aparecido. A amplitude de leitura do participante era o número máximo de palavras finais de que ele era capaz de se lembrar.

\section{O teste de amplitude sintática (SYSPAN)}

O teste de amplitude sintática, que foi originalmente elaborado por este estudo, foi também baseado no teste de amplitude de memória de leitura de Daneman e Carpenter (1980), acima descrito. Da mesma forma, o teste de amplitude sintática exigia que os participantes usassem as duas funções da memória de trabalho: processamento e 
armazenamento. O componente de processamento consistia em julgar a gramaticalidade das frases na terceira pessoa do presente simples, enquanto o componente de armazenamento consistia em manter e resgatar a palavra final de cada frase, como no seguinte exemplo:

He buys butter

The lady bring the key

Os participantes liam as frases em voz alta e, em seguida, julgavam-nas como gramaticalmente certas ou erradas. Após virem a tela branca, os participantes tinham que lembrar as últimas palavras das frases na ordem em que elas haviam aparecido. A amplitude de memória sintática de um participante foi considerada pelo número máximo de palavras lembradas na ordem de apresentação.

\section{O teste de amplitude de fala (SSPAN)}

Baseado em Daneman (1991) e Fortkamp (2000), o teste de amplitude de memória foi elaborado com 120 palavras nãorelacionadas e, como os participantes neste estudo eram de nível iniciante, a seleção das palavras seguiu os seguintes critérios: (1) as palavras deviam ser conhecidas dos participantes e foram extraídas do livro texto que eles estavam utilizando naquele momento; (2) somente palavras monossilábicas e dissilábicas foram selecionadas; (3) palavras semanticamente relacionadas foram evitadas dentro da mesma seqüência; e (4) palavras foneticamente similares foram também evitadas dentro de cada seqüência.

O número total de palavras foi organizado em seis conjuntos, cada um de duas, três, quatro, cinco e seis palavras. Cada palavra foi apresentada individualmente, no centro da tela do computador, por um intervalo de um segundo. Os participantes foram instruídos, em português, a lerem as palavras silenciosamente. Após 10 milésimos de segundo, a palavra seguinte aparecia na mesma posição da palavra anterior. Esse procedimento foi executado até que o conjunto terminasse e uma tela branca aparecesse acompanhada de um sinal sonoro e de pontos de interrogação. Isso sinalizava que o conjunto havia terminado. Os pontos de interrogação sinalizavam o número de palavras a serem lembradas e o número de frases a serem produzidas. 
Cada conjunto começava com uma seqüência de duas palavras, seguido de seqüências cada vez mais longas, até que uma seqüência de seis palavras fosse apresentada. Os participantes foram instruídos a usar cada palavra na sua forma exata, na ordem em que aparecia, para gerar frases sintática e semanticamente aceitáveis, em voz alta, em inglês. Não havia constrições em relação ao comprimento das frases a serem produzidas. Por exemplo, após ser apresentada a seguinte seqüência de palavras,

Desk road sun trip

um determinado participante produziu as seguintes frases:

I am near the desk

I went to a trip to POA last year

I can't see the sun today

There is a long road near my house

Após os participantes terem terminado o armazenamento de palavras e a produção de frases para um grupo, o pesquisador ou o participante pressionava uma tecla do computador e o próximo conjunto era apresentado, totalizando um número de 6 conjuntos contendo 120 palavras ao todo. O teste foi precedido de um treino que durou até o momento em que os participantes reportaram estar confortáveis e confiantes para realizá-lo.

A amplitude de fala dos participantes foi definida como o número máximo de palavras (de um total de 60) para as quais o participante era capaz de gerar uma frase gramatical usando a palavra apresentada em inglês. No presente estudo, as respostas dos participantes, que foram gravadas, foram analisadas e geraram dois escores de fala distintos: um rígido e um tolerante (DANEMAN, 1991). No primeiro, receberam crédito somente as palavras que foram lembradas na sua forma exata e na ordem em que apareceram. O escore tolerante de Daneman (1991) foi levemente modificado para acomodar o fato de que os participantes eram iniciantes em inglês. Nesse caso, não houve restrições em relação: (1) à gramaticalidade das frases produzidas; (2) à forma das palavras lembradas; e (3) à ordem de aparição da palavra lembrada. Conseqüentemente, toda frase produzida em qualquer ordem recebeu crédito. 


\section{Medidas de desempenho em L2}

\section{A tarefa de compreensão de leitura}

A tarefa de leitura proposta é uma adaptação da versão original de Daneman e Carpenter (1980), apresentada no Anexo 6. Uma pequena e simples narrativa foi desenvolvida para que os participantes pudessem ler sem dificuldades - tanto em relação ao vocabulário como em relação aos aspectos gramaticais (os participantes eram iniciantes do curso de Letras). Após a leitura da narrativa, que deveria ser feita apenas uma vez, os participantes responderam a questões relativas (a) aos pronomes, (b) ao tema e (c) a certos aspectos implícitos e explícitos sobre do texto. A pontuação dos participantes foi dada em relação à quantidade de acertos.

\section{A tarefa de produção oral}

Os participantes tiveram que fazer uma descrição de uma gravura colorida, tirada de um livro de gravuras, que mostrava uma família interagindo durante o café da manhã (Apêndice 7). Os participantes foram instruídos a descrever a gravura com o máximo de detalhes, dar informação em relação ao ambiente (cores e móveis), às pessoas (características físicas, idade, nomes) e às ações que as pessoas estavam fazendo (Apêndice 8). Eles foram encorajados a usar sua imaginação para adicionar informação e dar sua opinião pessoal sobre a mensagem que a gravura procurava revelar. Não houve limitação em relação ao tempo que os participantes tinham para efetuar a atividade de produção oral. Eles tiveram dez minutos para planejar sua fala antes da atuação e puderam tomar notas. Contudo, não foi permitido consultá-las durante a fase de gravação. No entanto, eles puderam olhar para a gravura enquanto a descreviam. Os participantes foram encorajados a usar todo o seu comando na língua inglesa para realizar a tarefa.

Dois critérios básicos foram adotados em relação ao tipo de tarefa ministrado e à condição sob a qual a tarefa foi desenvolvida. Em relação ao primeiro item, a tarefa de descrição foi escolhida devido às seguintes razões: (1) é uma tarefa do tipo monólogo e, portanto, adequada para extrair fala que poderia ser analisada em nível de fluência (veja FREED, 1995; LENON, 1990; FORTKAMP, 2000, por exemplo); e (2) é um tipo 
de tarefa que vem sendo usada na extração de fala tanto em L1 como em L2 (veja ORTEGA, 1999). Em relação ao segundo quesito, a condição de planejamento estratégico, um tempo para o planejamento foi permitido porque essa condição tem se mostrado eficaz no desempenho oral de aprendentes (veja FOSTER e SKEHAN, 1996; MEHENERT, 1998; SKEHAN e FOSTER, 1995, entre outros) e foi nosso propósito maximizar o desempenho de nossos participantes, gerando condições para que eles produzissem fala fluente, complexa e gramaticalmente correta.

O desempenho dos aprendizes foi avaliado em termos de fluência e precisão. Fluência é vista como performance continuada e como comunicação que evita reparos (SKEHAN, 1996, p. 304). A fluência foi acessada por duas medidas, velocidade da fala unprunned e velocidade da fala pruned (LENNON, 1990; ORTEGA, 1999). A velocidade da fala unprunned foi calculada dividindo-se o número total de unidades semânticas (palavras completas e parciais), incluindo repetições, pelo número total de tempo (em segundos) em que os participantes atuaram oralmente. O resultado foi então multiplicado por 60. O mesmo procedimento foi utilizado para calcular a velocidade da fala pruned. Nesta medida, no entanto, repetições (excluindo aquelas de efeito retórico) foram excluídas. A velocidade da fala, tanto pruned quanto unpruned, é considerada uma medida global para acessar fala fluente (EJZEMBERG, 1992; FREED, 1995; LENNON, 1990; RIGGENBACK, 1989; TEMPLE, 1992; FORTKAMP, 2000). Ademais, existe a tendência no campo da pesquisa em produção oral de que medidas globais sejam utilizadas (FOSTER e SKEHAN, 1996).

Precisão, nessa pesquisa, é conceituada como desempenho sem erros, fato que leva ao uso de formas relativamente simples e bem controladas com o objetivo de atingir um desempenho mais correto na língua-alvo. Esse construto é associado a uma orientação mais conservadora (foco nas formas) e diz respeito ao controle em um nível particular de interlíngua (SKEHAN, 1996, p. 304). Nesta pesquisa uma medida geral para acessar precisão foi utilizada: número de erros por 100 palavras (veja FOSTER e SKEHAN, 1996; FORTKAMP, 2002). Todos os erros considerando sintaxe, morfologia e escolhas lexicais foram computados. Palavras mal pronunciadas não foram consideradas como erro, a menos que a palavra não fosse compreendida. Para expressar o número total 
de erros por 100 palavras, o número total de erros foi dividido pelo número total de palavras produzidas e então multiplicado por 100.

\section{A tarefa de sintaxe}

Semelhantemente à tarefa de produção oral, na tarefa de sintaxe os participantes receberam uma seqüência de figuras em que tinham que narrar os eventos na rotina diária de um homem (Robert) e de uma mulher (Caroline). No entanto, essa atividade é distinta da atividade de produção oral em dois aspectos: (1) ela induzia os participantes a usar uma estrutura sintática específica: a terceira pessoa do singular no presente; e (2) ela exigia que os participantes produzissem discurso somente no nível da frase, uma vez que eles tinham que descrever apenas a seqüência de ações na figura. A mesma estrutura sintática, o presente simples, foi usado pelas pesquisadoras para elaborar o teste de amplitude sintática que os participantes tinham realizado anteriormente a esta atividade de sintaxe.

Antes de receberem as figuras, os participantes tiveram uma fase instrucional de dez minutos sobre o uso do presente simples, mais especificamente da terceira pessoa, para descrever rotinas. Primeiramente, planejávamos avaliar o desempenho sintático dos aprendizes apenas com respeito ao uso do presente simples. Entretanto, por causa de um excelente desempenho de todos os participantes no uso dessa estrutura, decidimos medir o desempenho sintático levando em consideração qualquer erro gramatical na fala dos participantes. Oferecemos, na seção de discussão dos resultados, uma explicação para a excelência no desempenho dos aprendizes na utilização da terceira pessoa do singular.

As amostras de fala foram gravadas individualmente e a precisão foi medida levando-se em conta o número total de erros em 100 palavras. Os participantes não tiveram a oportunidade de praticar ou planejar. Foram instruídos a darem início à gravação de sua seqüência narrativa imediatamente após receberem as figuras.

\section{A tarefa de percepção fonológica}

Antes que os participantes começassem essa tarefa, a pesquisadora perguntou-lhes se já tinham trabalhado com discriminação dos sons 
de 's' plural ou 's' terceira pessoa singular do presente simples, pergunta para a qual todos deram uma resposta negativa. No momento em que este estudo foi conduzido, todos os participantes declararam não ter problemas de audição.

Uma das pesquisadoras iniciou a primeira parte da pesquisa com uma seção de instrução, que durou dez minutos, sobre os diferentes sons de 's' (/s/, /z/, /Iz/) no plural das palavras ou na terceira pessoa dos verbos no presente simples (Apêndice 10). Foi pedido aos participantes que pronunciassem as palavras de cada grupo de som (/s/, /z/, /Iz/) para certificar-se de que eles podiam perceber a diferença entre eles. Em seguida, os participantes foram convidados a concluir quais eram as regras de pronúncia daqueles sons. Os alunos puderam usar L1 no momento de explicitar as regras. Todos foram capazes de organizar as regras de uma maneira mais informal. A pesquisadora, então, concluiu esta etapa de instrução explicitando as regras de uma forma mais sistemática com os participantes. Antes de avançarem para o passo seguinte (treinamento de curta duração), foi dada aos participantes a oportunidade de fazerem perguntas e esclarecerem dúvidas.

\section{Treinamento de curta duração}

Os participantes foram, então, submetidos a uma fase de treinamento (Apêndice 10), usando a mesma folha de atividades. Os participantes ouviram seis blocos de palavras, cada bloco contendo cinco palavras. Em todos os blocos os participantes tinham que sublinhar a palavra que não pertencia ao bloco com relação ao modo como eram pronunciados os sons de '-s'. Os participantes foram informados de que ouviriam cada bloco de palavras apenas uma vez. A pesquisadora fazia uma pausa após cada bloco de palavras ter sido pronunciado para checar a resposta junto aos participantes. Se um participante tivesse cometido um erro, a pesquisadora pedia a ele/ela que voltasse à regra para checar o porquê do erro. Somente quando a regra estivesse clara é que os participantes iriam para o bloco seguinte. Quando o treinamento de curta duração terminou, foi pedido aos participantes que guardassem suas folhas com os exercícios e não fizessem uso delas em momento algum até que o teste tivesse terminado. 


\section{Teste de percepção}

Os participantes receberam uma outra folha de exercícios (Apêndice 11). Foi dito a eles que ouviriam trinta palavras com diferentes pronúncias (/s/,/z/ ou /Iz/) de '-s'. Eles tinham que colocar um símbolo ( $\mathrm{O}$ na coluna correspondente ao som que eles tivessem ouvido (/s/,/z/ ou /Iz/). Os participantes foram informados de que ouviriam as palavras sendo pronunciadas apenas uma vez e que a fita cassete só pararia de tocar após a última (trigésima) palavra ter sido pronunciada. Os participantes ouviram o modelo '0' como forma de checar que tinham entendido as instruções, as quais foram dadas em L1. A resposta para o item '0' já estava dada. As trinta palavras deste teste foram gravadas por uma falante nativa de inglês norte-americano. Havia um intervalo de 5 segundos entre o pronunciamento de uma palavra e outra. Os participantes não tiveram acesso à forma escrita das palavras, a fim de evitar interferência da forma escrita com o teste de percepção. O resultado final dos participantes foi medido pelo número total de sons de '-s' que eles conseguiram perceber corretamente.

\section{Resultados e Discussão}

Os resultados obtidos através da aplicação de uma bateria de quatro testes de memória de trabalho e quatro tarefas em L2 foram complexos e não-sistemáticos, convidando as pesquisadoras a reavaliar as hipóteses previamente formuladas. A apresentação e a discussão dos resultados está organizada da seguinte forma: (1) correlações entre o OSPAN e tarefas em L2, e correlações entre testes específicos de memória e tarefas em L2; (2) memória de trabalho e compreensão de leitura; (3) memória de trabalho e sintaxe; (4) memória de trabalho e produção oral; e (5) memória de trabalho e percepção fonológica.

A Tabela 2 abaixo traz os resultados obtidos através da Pearson Product Moment Correlations, mostrando uma correlação significante entre o OSPAN e a tarefa de leitura (.614*); a tarefa de sintaxe (-.697*), e a medida de precisão na tarefa de produção oral (-.597*). 


\begin{tabular}{lllllll}
\hline & Leitura & Sintaxe & Fonologia & Produção Oral & \\
\hline & & & & Fluência & Fluência Acurácia \\
& & & & prunned & unprunned & \\
\multirow{2}{*}{ OSPAN } & $0.614^{*}$ & $-0.697^{*}$ & 0.317 & 0.466 & 0.460 & $-0.597^{*}$ \\
\hline
\end{tabular}

TABELA 2 - Correlações entre a medida geral de capacidade de memória de trabalho e medidas em tarefas em L2.

Na Tabela 3, os resultados mostram uma correlação significante entre o RSPAN e a tarefa de sintaxe (-.667*); o SSPAN rígido e a tarefa de sintaxe (-.681*); e entre o SSPAN rígido e a tarefa de produção oral. No entanto, a questão não pode ser resolvida, uma vez que os mesmos dados não fornecem uma correlação significante entre o RSPAN e a atividade de compreensão de leitura, entre o SYSPAN e a tarefa de sintaxe, entre os SSPANs (rígido e tolerante) e as medidas de fluência na tarefa de produção oral e, ainda, entre o SSPAN e a tarefa de percepção fonológica.

A combinação desses resultados não parece confirmar nenhuma das duas hipóteses formuladas na introdução, uma vez que não apontam nem para uma natureza totalmente unitária e geral da capacidade de memória de trabalho, nem para uma natureza de especificidade dessa capacidade. As subseções seguintes vão abordar cada uma dessas questões, fornecendo explicações prováveis para as correlações encontradas ou para a falta delas.

\begin{tabular}{|c|c|c|c|c|c|c|}
\hline & \multirow[t]{3}{*}{ Leitura } & \multirow[t]{3}{*}{ Sintaxe } & \multirow[t]{3}{*}{ Fonologia } & \multicolumn{3}{|c|}{ Produção Oral } \\
\hline & & & & Fluência & Fluência & Precisão \\
\hline & & & & prunned & unprunned & \\
\hline RSPAN & 0.268 & $-0.667^{*}$ & 0.244 & 0.525 & 0.527 & -0.338 \\
\hline SYSPAN & 0.099 & -0.460 & 0.407 & 0.250 & 0.204 & -0.298 \\
\hline SSPAN & 0.328 & $-0.681^{*}$ & 0.117 & 0.452 & 0.482 & $-0.825^{* *}$ \\
\hline \multicolumn{7}{|l|}{ Rígido } \\
\hline SSPAN & -0.043 & -0.528 & -0.86 & 0.301 & 0.354 & -0.484 \\
\hline Tolerante & & & & & & \\
\hline
\end{tabular}

TABELA 3 - Correlações entre as medidas específicas de capacidade de memória de trabalho e medidas em tarefas em L2. 


\section{Capacidade de memória de trabalho e compreensão de leitura}

Conforme argumentado até então, os testes de amplitude da memória de trabalho medem a capacidade de um indivíduo em armazenar informações que serão usadas em futuros processamentos. Comparações feitas entre os resultados obtidos pelos participantes nos testes de memória de trabalho e certas tarefas propostas apresentaram os seguintes resultados: (a) houve uma correlação significante entre o teste envolvendo soma-palavra (OSPAN) e a tarefa de compreensão de leitura $\left(, 614^{*}\right)$. Esse resultado poderia ser um indicativo de que os participantes com maiores amplitudes de memória podem controlar melhor a alocação dos recursos necessários para o processamento das informações. Tal fato facilitaria a tarefa de armazenar e extrair as informações necessárias, tornando o processo mais rápido e preciso, o que poderia vir a minimizar a ocorrência de erros; (b) uma correlação significante também foi observada entre os testes de amplitude de memória em leitura e as tarefas de sintaxe (-.667), medidas obtidas pelos números de erros apresentados. Esse resultado pode corroborar o seguinte aspecto: as dificuldades sintáticas, fator que pode sobrecarregar a memória de trabalho na hora do processamento, foram menos cruciais para os participantes com maiores amplitudes de memória (JUST e CARPENTER, 1987), facilitando-lhes a realização das tarefas. Além disso, esse fato pode indicar que os participantes com maiores amplitudes de memória de trabalho também poderiam possuir competências lingüísticas implícitas maiores, o que por sua vez também levaria a uma incidência menor dos erros. Competência lingüística implícita envolve o conhecimento de fonologia, morfologia, sintaxe e de aspectos semânticos da língua (PARADIS, 2000).

Enquanto os aspectos anteriormente relatados confirmam as hipóteses encontradas na literatura sobre memória de trabalho, para nossa surpresa apenas uma baixa correlação foi encontrada entre os testes de amplitude de memória em leitura e as tarefas de compreensão de leitura. Uma possível explicação para tal resultado é que o texto usado para a leitura subestimou o nível de inglês dos participantes, uma vez que havia sido desenvolvido para iniciantes. Sendo assim, as tarefas exigidas deixaram de ser complexas, não apresentando dificuldade de processamento, nem mesmo para os participantes com baixa amplitude de memória, possibilitando-lhes executar as tarefas 
estratégica e habilmente. Levando-se em consideração que possíveis diferenças entre participantes com baixa/alta amplitude de memória são mais claramente observadas em tarefas que impõem um peso maior para o processamento (MIYAKE e FRIEDMAN, 1998), uma vez que tal peso deixou de existir, o resultado obtido passa a ser justificado.

Mais investigações, com os mesmos participantes, deveriam ser conduzidas para que os resultados pudessem ser ampliados e confirmados, principalmente levando-se em consideração que "os achados correlacionais por si só possuem pouco valor explanatório" (HARRINGTON, 1992, p. 124). Devido ao fato de que este estudo é de natureza correlacional, não experimental, os resultados são susceptíveis de interpretações causais e não axiomáticas. Entretanto, apesar dessa limitação inerente à investigação, os dados correlacionais obtidos parecem fornecer uma saída importante para a investigação das dimensões na variação em proficiência de L2 (MIYAKE e FRIEDMAN, 1998).

\section{Capacidade de memória de trabalho e sintaxe}

A correlação significativa entre a medida geral de memória de trabalho e as medidas na tarefa de sintaxe sugerem que participantes com uma ampla capacidade de memória de trabalho são também aqueles mais capazes de lidar com as exigências de processamento e armazenamento de informação inerentes à atividade de produção oral. Além disso, uma correlação tão significativa parece indicar que para predizer o desempenho sintático dos indivíduos, o teste de amplitude de memória não precisa conter um componente de processamento estritamente sintático, uma vez que o OSPAN, uma medida geral de capacidade de memória de trabalho, mostrou ser um índice eficaz do desempenho sintático dos participantes deste estudo. Tais resultados podem ser interpretados como evidência de que a natureza da relação entre memória de trabalho e sintaxe é geral, corroborando, dessa forma, a primeira hipótese deste estudo.

Quanto à correlação entre o teste de amplitude de leitura e a tarefa de sintaxe, este dado se assemelha aos resultados de Harrington (1992), em que uma correlação significativa também foi encontrada entre o teste de amplitude de leitura e medidas de gramática em L2, e também os de Miyake e Friedman (1998), que representam uma contribuição 
notável para o campo de sintaxe e memória de trabalho em L2. Podese sugerir que indivíduos com uma maior amplitude de memória de trabalho em leitura são mais hábeis em produzir e compreender estruturas sintáticas que aqueles cuja memória de trabalho é inferior. Supostamente, sua eficiência em compreender sentenças enquanto, simultaneamente, armazenavam palavras, durante o teste de amplitude de memória, estava também presente quando tiveram de produzir sentenças durante a tarefa de descrição de uma seqüência narrativa, quando tiveram que selecionar a gramática e o léxico apropriados enquanto, ao mesmo tempo, mantinham produtos intermediários dessas sentenças em mente.

Outra importante correlação a ser explicada é aquela entre o teste de amplitude de fala (estrito) e a tarefa de sintaxe. Como os resultados mostram, os indivíduos com ampla capacidade de memória de trabalho foram mais bem sucedidos nas tarefas de armazenamento e processamento durante a produção de sentenças gramaticalmente corretas, sendo também os mais precisos durante a tarefa de sintaxe, a qual exigia semelhantes processos cognitivos. Isso se deve ao fato de o teste de amplitude de fala conter ambos os componentes de produção e precisão, similarmente à tarefa de sintaxe, o que tornou, neste estudo, o teste de amplitude de memória de trabalho um eficiente índice de desempenho sintático dos aprendizes.

Entretanto, ao contrário do que tinha sido previsto na introdução, houve uma falta de correlação entre o teste de amplitude sintática e a tarefa de sintaxe. Uma tentativa de explicação para tal fato é que o teste de amplitude sintática, especialmente elaborado para este experimento, não provou ser um bom índice de desempenho sintático porque ele não incorporou os mesmos aspectos, ou todos os aspectos gramaticais que foram considerados quando a precisão dos aprendizes foi medida na tarefa de sintaxe. Enquanto na tarefa de sintaxe a precisão foi medida de uma forma geral (todos os erros gramaticais foram considerados), no teste de amplitude sintática os participantes tiveram apenas que julgar frases no presente simples, representando somente uma forma gramatical medida entre muitas que foram empregadas durante a tarefa de sintaxe.

Outro aspecto parece crucial para se explicar o porquê de o teste de amplitude sintática ter apresentado problemas, o que conseqüentemente resultou na falta de correlação entre este teste e a tarefa de 
sintaxe: não havia um componente de produção no teste, apenas um componente de compreensão. Conforme já explicado, os participantes tiveram apenas que julgar se as sentenças eram gramaticalmente corretas ou erradas e não tiveram que produzir sentenças em L2. Por outro lado, durante a tarefa de sintaxe, foi solicitado aos participantes que produzissem frases para narrar uma seqüência de eventos. Dessa forma, o teste de amplitude sintática não poderia vir a ser um bom índice de desempenho sintático, pois ele não exigiu dos participantes o mesmo envolvimento cognitivo que a tarefa de sintaxe.

Assim, nós concluímos que o teste de amplitude sintática, elaborado especialmente para este estudo, não foi um índice eficaz de desempenho sintático. Cabe a experimentos futuros elaborar testes mais adequados de amplitude sintática, tendo em mente dois objetivos principais: a inclusão de variadas estruturas gramaticais e a inserção de um componente de produção.

\section{Capacidade de memória de trabalho e fonologia}

Da mesma forma que com outros resultados, o teste de sons também apresentou efeitos de teto. A pontuação mais baixa foi 16, de um total de 30, ainda assim mais que 50\%; e a pontuação mais alta foi 29 , de um total de 30 , ficando a média do grupo em 24 , o que significa uma média de $80 \%$ de respostas corretas. Diferenças individuais, portanto, não apareceram, o que foi um indicador razoável para se rotular a tarefa como sendo uma tarefa não-complexa. Miyake e Shah (1999) afirmam que "tarefas complexas podem ser caracterizadas como sendo tarefas sob controle cognitivo, envolvendo múltiplas etapas de processamento e exigindo acesso rápido a uma grande quantidade de informação" (p. 426). Eles acrescentam também que

é importante que não deixemos de estudar tarefas que tenham somente uma dessas propriedades, mas que tentemos, por fim, entender a operação da memória de trabalho em tarefas que possuem várias ou todas essas propriedades.

Uma vez que na tarefa de fonologia os participantes tinham apenas que perceber o som correto produzido no '-s' final das palavras, os critérios básicos que caracterizam a tarefa como complexa não foram atendidos. Assim, até mesmo o participante que tinha apresentado o 
resultado mais baixo no teste OSPAN foi capaz de obter um resultado maior que 50\% nesta tarefa de percepção fonológica, causando, assim, um efeito de teto. Outros fatores também poderiam ajudar a explicar tal efeito, sendo dois deles: (1) treinamento de curta duração; e (2) a discriminação de som.

\section{Treinamento de curta duração}

O fato de os participantes terem tido um treinamento de curta duração logo após a instrução pode ser considerado como um outro fator de grande contribuição para os bons resultados dos participantes e, assim, para a falta de correlação. Logan e Pruitt (1995) definem treinamento de curta duração como "treinamento que não vai além de uma seção" (p. 364), que foi o tipo de treinamento ao qual os participantes foram submetidos ao realizarem o teste. Eles também mostram os resultados de alguns estudos nos quais o treinamento de curta duração foi usado, levando a resultados positivos. Na mesma linha, Anderson (1995) relata um estudo sobre os efeitos de espaçamento e testes. Três grupos foram comparados. Um grupo em condição zero de prazo (os participantes fizeram todos os estudos em um dia), outro em um dia de prazo após o treinamento e um último grupo, em uma condição de trinta dias de prazo após o treinamento. Ele diz que "os grupos com menores intervalos entre os ciclos tiveram um resultado melhor no início, refletindo um efeito padrão de retenção" (p. 243). Embora os resultados tenham sido bem-sucedidos, os autores questionam as limitações do treinamento de curta duração e os efeitos de espaçamento, uma vez que não está claro se os resultados teriam o mesmo êxito se uma checagem fosse feita um determinado tempo depois. Isso para dizer que, no teste realizado, esse pode ter sido um fator de grande contribuição para o efeito de teto, uma vez que os participantes foram testados imediatamente após o treinamento. Certamente não um fator único, mas que, acoplado à tarefa de discriminação de sons (melhor descrita abaixo), foi responsável pelo sucesso da tarefa entre os participantes e pelo apagamento das diferenças individuais que pudessem surgir. Uma nova testagem que levasse em conta um espaçamento de trinta dias, como sugere Anderson (1995), poderia confirmar (ou não) o efeito do espaçamento na tarefa de percepção de sons. 
Tendo sido a testagem com maior espaçamento uma limitação deste teste, por motivo de nosso tempo com os participantes ter sido um tanto restrito (um total de duas semanas para a realização de todos os testes), fica aberta a questão sobre quão diferentes teriam sido os resultados, tivesse uma outra testagem ocorrido após um mês.

Passamos, assim, para um segundo item que parece ter sido também um grande responsável pelo efeito de teto: a discriminação de som.

\section{Discriminação de som}

Foi pedido aos participantes que discriminassem os sons finais de '-s' (/s/,/z/ or /Iz/) em verbos na terceira pessoa do singular. Conforme previsto pelo Modelo de Best (1995)-Perception of Assimilation Model- citado por Aoyama (2003),

se duas categorias não nativas são assimiladas a duas categorias nativas, é esperado que a discriminação seja excelente. Por outro lado, se duas categorias não nativas são assimiladas a uma única categoria nativa, é esperado que a discriminação seja precária (p. 252).

Na tarefa fonológica para este estudo, foi pedido aos participantes que discriminassem três sons não nativos que encontraram três sons correspondentes na L1 dos participantes, não colocando, assim, grande dificuldade no processamento dos sons e na realização da tarefa.

Embora os participantes tivessem declarado não terem tido instrução com relação à discriminação de sons anteriormente, é provável que fatores como o efeito da instrução e do treinamento, o espaço mínimo de tempo entre treinamento e teste, e a excelente discriminação de sons causada pela presença dos mesmos sons na representação mental dos participantes na L1 tenham, juntos, causado o efeito de teto obtido. Assim, uma nova aplicação da tarefa fonológica, testando sons que não fazem parte do sistema fonológico na L1 dos participantes, poderia fornecer dados que mostrassem se foi a discriminação de sons, por si só, o item responsável por tal efeito de teto.

Inicialmente a pesquisadora partiu da hipótese de que a medida de amplitude oral pudesse capturar o aspecto fonológico, uma vez que fonologia é parte da percepção e produção de fala, conforme mostra Levelt em seu modelo. Entretanto, uma vez que o teste fonológico teve foco na percepção, enquanto a medida de amplitude oral focou a 
produção, eles não compartilharam de um componente comum às tarefas. Portanto, uma medida de amplitude oral que leve em conta tanto o processamento quanto o armazenamento nessa habilidade poderia ser desenvolvida a fim de verificar se há uma relação entre capacidade de memória de trabalho nas tarefas de percepção da fala.

\section{Capacidade de memória de trabalho e produção oral}

Os resultados demonstraram uma significante correlação entre capacidade de memória de trabalho, medida pelo teste OSPAN, e o teste de produção oral em nível da precisão $\left(-0.597^{*}\right)$. Tal resultado pode sugerir que os participantes que têm um alto grau geral de capacidade de armazenamento e processamento também são capazes de lidar, com sucesso, com o armazenamento e processamento de informação para produzir mapeamentos gramaticais corretos e fazer buscas lexicais corretas on-line. Além do mais, a correlação encontrada também pode ser evidência para o fato de que a capacidade de memória de trabalho é um recurso unitário, dando suporte, conseqüentemente, à visão geral de memória de trabalho (TURNER e ENGLE, 1989; ENGLE, KANE e TUHOLSKI, 1999). No entanto, o teste de amplitude de memória de trabalho da fala, medido por seu escore estrito, revelou uma correlação muito mais robusta $\left(-0.825^{*}\right)$ entre capacidade de memória de trabalho e fala gramaticalmente correta on-line, fato que corrobora a visão de que aqueles com capacidade de memória de trabalho mais ampla são aqueles indivíduos menos passíveis de cometerem erros gramaticais e lexicais durante o desempenho oral (veja FORTKAMP, 2000). Esse resultado permite-nos fazer duas considerações: uma em relação à discussão em torno da questão sobre ser a memória de trabalho específica à tarefa ou pertencente ao domínio geral, e outra em relação à discussão sobre capacidade de memória de trabalho e proficiência em L2. Quanto à primeira questão, considerando-se os resultados de correlação significante, tanto das medidas do OSPAN com o teste de amplitude da fala (medido por seu escore estrito) quanto da correlação significante com o desempenho oral correto, talvez haja espaço para também aceitar-se a visão que afirma que a memória de trabalho possa ser tanto de caráter geral quanto de caráter específico à tarefa desempenhada (MIYAKE e SHAH, 1999), sendo que, neste caso, o teste 
de memória de trabalho na habilidade oral (escore estrito) foi mais eficiente em prever produção oral gramaticalmente correta. Neste estudo, esse resultado pode ser explicado pelo fato de que o teste de amplitude de memória de trabalho da fala (medido pelo escore estrito) incluiu uma medida de precisão no componente de processamento do teste, já que os escores dos participantes foram indexados levando-se em consideração somente as frases corretas, contendo as palavras corretas.

Em relação à segunda questão, relação entre medidas de memória de trabalho e proficiência na língua, é interessante mencionar que apesar do fato de os escores estritos e lenientes do teste de amplitude de memória de trabalho da habilidade da fala terem correlacionado de maneira significante $\left(0,860^{* *}\right)$, uma correlação não significante foi encontrada entre os escores leniente e a performance oral gramaticalmente correta dos participantes $(0,484)$, medida pelo número de erros produzidos. É importante ressaltar que o teste de memória de trabalho da fala em seu escore leniente não incluiu uma medida de precisão. Além do mais, a média de desvio no escore leniente $(27,3)$ mostra maior homogeneidade no grupo de participantes do que a média do escore estrito $(22,0)$. Portanto, diferenças individuais não emergiram de maneira significativa. Conseqüentemente, podemos concluir que a amplitude de memória de trabalho em L2, medida pelo escore do teste de fala na sua versão estrita, pode ser uma função do grau de conhecimento na língua-alvo, medido neste estudo em nível de precisão (MIYAKE e FRIEDMAN, 1998), o que quer dizer que a questão do conhecimento em L2 tem seu papel ao determinar a capacidade de memória de trabalho dos participantes. Portanto, podemos tentativamente sugerir que, sendo nossos participantes iniciantes, sua capacidade de memória de trabalho pode estar aberta a melhorias (até um certo ponto), à medida que os mesmos incrementam seu conhecimento geral do sistema lingüístico. Ericsson e Delaney (1998) declaram que existe a possibilidade de haver expansão na capacidade de memória de trabalho através da aquisição de informações específicas ao domínio. Isso pode ser também verdadeiro no caso do desenvolvimento da fala, já que a capacidade de memória de trabalho dos indivíduos pode ser expandida como resultado de novos conhecimentos adquiridos, levando a uma maior automatização do sistema (HARRINGTON, 1992; BERQUIST, 1998; HARRINGTON E SAWYER, 1992). 
Também tínhamos por objetivo investigar a relação entre o teste de amplitude de memória de trabalho da fala (escores estrito e leniente) e uma tarefa de produção oral em nível da fluência. Os resultados do teste de amplitude de memória de trabalho, em ambos os escores, não correlacionaram de maneira significante com as duas medidas adotadas para avaliar fluência nesta pesquisa - velocidade da fala unprunned e velocidade da fala prunned. Este resultado não era esperado e não corrobora aqueles de Daneman (1991) e Fortkamp (1998, 2000). Buscando razões plausíveis para explicar essa falta de correlação, trazemos à discussão as seguintes questões: (1) o papel do planejamento estratégico antes da performance oral; e (2) a natureza do teste de amplitude de trabalho da fala.

Em relação à primeira questão, uma possível explicação sobre a falta de correlação diz respeito ao papel do planejamento estratégico e seu impacto na performance oral dos participantes. Ao ter oportunidade para planejar estrategicamente o ato da fala, os participantes tiveram a oportunidade de escolher, a priori, itens lexicais e mapeamentos gramaticais que seriam necessários para elaborar suas intenções comunicativas. Desse modo, essas escolhas, durante esse processo, foram recentemente ativadas e, portanto, estariam "frescas" na memória de longo prazo dos participantes (D'ELY, 2004). Sabe-se que o resgate de informação é um dos mecanismos (além da codificação e manutenção) que formam a base para a memória de trabalho (MIYAKE e SHAH, 1999) - "a rapidez e a precisão da recuperação de informação (retrieval) é uma função do nível de ativação do item alvo" (MIYAKE e SHAH, 1999, p. 414). Conseqüentemente, nossos participantes, independentemente das diferenças individuais na capacidade de memória de trabalho, podem ter obtido vantagem da condição de planejamento, uma vez que os itens a serem utilizados já haviam sido escolhidos, fato que otimizou a utilização dessas escolhas on-line. Essa explicação sugere que seria extremamente relevante fazer futuras incursões na relação entre capacidade de memória de trabalho e planejamento estratégico e seu impacto no desempenho oral dos aprendizes.

A segunda questão diz respeito a uma falha metodológica na implementação do teste de amplitude de memória de trabalho. A medida para acessar fluência (velocidade da fala unpruned e pruned) é uma medida temporal, a qual foi indexada dividindo-se o número total 
de palavras produzidas pelo total do tempo do desempenho oral dos aprendizes (em segundos) e então multiplicando o resultado por sessenta. Essa medida leva em consideração a rapidez e o curso natural da fala. Quanto maior a média, mais fluente é a fala. Assim sendo, o tempo é uma variável na própria medida. Uma possível explicação para a falta de correlação significante é o fato de que o tempo não foi uma variável que tenha sido considerada no teste de amplitude de memória de trabalho, nem no escore estrito nem no escore leniente, já que não houve pressão de tempo no período em que os participantes estavam relembrando as palavras e fazendo as frases com as mesmas. Esse fato leva-nos a mencionar uma questão amplamente discutida no âmbito da memória de trabalho: como o uso de estratégias pode influenciar o desempenho no teste de amplitude de memória de trabalho (TURLEY-AMES e WHITFIELDE, 2003; MCNAMAR e SCOTT, 2001; ERICSSON e KINTSCH, 1995; WEISSHEIMER e FORTKAMP, 2004, entre outros) e, conseqüentemente, até que ponto a amplitude de memória de trabalho dos participantes reflete a capacidade ou o uso efetivo de estratégias ou se ambos os construtos interagem efetivamente na memória de trabalho (veja WEISSHEIMER e FORTKAMP, 2004). Como não houve pressão de tempo, é possível tentativamente sugerir que os participantes tenham feito uso de estratégias, 'inflando' artificialmente sua amplitude de memória de trabalho e resultando, assim, na perda do poder de prognóstico entre medidas de memória de trabalho e escores de fluência. Portanto, se o objetivo é investigar a relação entre capacidade cognitiva e performance em tarefas em L2, pesquisadores devem considerar como melhor controlar a variabilidade do uso de estratégias ao acessar medidas de amplitude de memória de trabalho. Isso talvez possa ocorrer incluindo-se um componente que restrinja o tempo dos participantes ao processar a informação desejada.

\section{Considerações Finais}

Como qualquer estudo em pequena escala, os resultados apresentados aqui são necessariamente modestos e sugestivos, em vez de conclusivos. Entretanto, acreditamos que a presente investigação fornece novas alternativas para futuros estudos sobre memória de trabalho e desempenho em tarefas de L2. 
Quanto à discussão sobre a natureza específica ou geral da capacidade de memória de trabalho, proposta na introdução deste artigo, os resultados desta investigação não fornecem evidências para um posicionamento a favor de uma natureza exclusivamente unitária ou específica da capacidade de memória de trabalho. Como mencionamos na seção dos resultados, a medida geral de capacidade de memória de trabalho, medida pelo OSPAN, correlacionou significativamente com algumas tarefas em L2 - leitura, sintaxe e produção oral - mas não com todas elas, como havia sido previsto na primeira hipótese. Da mesma forma, as medidas específicas de capacidade de memória de trabalho (RSPAN, SSPAN, SYSPAN) correlacionaram com apenas duas tarefas correspondentes em L2 sintaxe e produção oral - mas não com todas as tarefas, como havia previsto a segunda hipótese deste estudo.

Conseqüentemente, parece-nos plausível apontar para uma natureza híbrida da relação entre a capacidade de memória de trabalho e o desempenho em tarefas em L2. Essa discussão sobre a natureza unitária ou específica da capacidade de memória de trabalho tem estado presente na literatura e, embora pesquisadores tenham se dividido entre proponentes da visão unitária ou não-unitária, nenhuma abordagem consistente foi oferecida até agora em favor de uma ou outra visão (MIYAKE e SHAH, 1999). Portanto, parece-nos conveniente abandonar essa dicotomia simplista - geral versus específica - e apontar para uma relação mais complexa, que necessita de maior investigação. Nesse sentido, estudos correlacionais como este, que visam explicar a natureza dos efeitos gerais e específicos encontrados nos dados, em vez de simplesmente aderir a uma visão unitária ou não-unitária da capacidade de memória de trabalho, têm muito a contribuir para essa discussão.

Em função da natureza exploratória do presente experimento, algumas dificuldades foram encontradas, possivelmente influenciando os resultados. Primeiramente, o fato de que os participantes deste estudo eram de nível iniciante e de que todos os testes de memória de trabalho foram aplicados em L2, pode ter gerado uma carga maior em suas capacidades cognitivas, afetando os resultados. Portanto, investigações futuras poderiam considerar a possibilidade de aplicarem-se os testes tanto em L1 quanto em L2 para chegarem-se a conclusões mais sólidas sobre essa relação. Além disso, seria 
interessante, como já mencionado, investigar se a capacidade de memória de trabalho em L2 aumenta em função da crescente proficiência na língua-alvo. Esse objetivo poderia ser alcançado replicando-se o presente estudo dentro de um modelo longitudinal. Finalmente, a amostra reduzida deste estudo não permite que as pesquisadoras generalizem os resultados a outras populações de aprendizes de L2. Assim, futuras investigações poderiam também considerar uma amostra mais representativa de participantes.

Em suma, a análise feita neste estudo permite que as pesquisadoras extrapolem as conclusões, oferecendo algumas implicações pedagógicas. Educadores deveriam levar em consideração o fato de que indivíduos possuem uma capacidade de memória de trabalho limitada, além do fato de que diferem na maneira com que alocam seus recursos atencionais de acordo com o grau de complexidade que a tarefa lhes impõe. Uma das questões que permeia essa discussão é como lidar com essas diferenças em sala de aula e como ter isso sempre em mente quando da seleção, elaboração e implementação dos materiais. Aí reside um dos maiores desafios do processo de aprendizagem e ensino.

\section{Referências Bibliográficas}

ANDERSON, J. R. Cognitive psychology and its implications. New York: Freeman, 1990.

ANDERSON, J. R. Learning and memory: an integrated approach. New York: John Wiley and Sons, 1995.

ASHCRAFT, M. Human memory and cognition. New York: Harper Collins, 1994.

ATKINSON, R. C.; SHIFFRIN, R. M. Human Memory: A proposed system and its control processes. In: SPENCE, K. W. (Ed.). The psychology of learning and motivation: Advances in research and theory. New York: Academic Press, v. 2, p. 89-195, 1968.

AOYAMA, K. Perception of syllable-initial and syllable-final nasals in English by Korean and Japanese speakers. Second Language Research, v. 19, p. 251265, 2003.

BADDELEY, A. D. Working memory. Oxford: Clarendon Press, 1986. 
BADDELEY, A. D. Human memory: Theory and practice. Hove, UK: Lawrence Erlbaum Associates, 1990.

BADDELEY, A. D. Is working memory working? Quarterly Journal of Experimental Psychology, 44A, p. 1-31, 1992.

BADDELEY, A. D.; HITCH, G. Working memory. In: BOWER, G. A. (Ed.). The psychology of learning and motivation. New York: Academic Press, v. 8, p. 47-89, 1974.

BAPTISTA, B. Aspectos da Teoria Cognitiva: Aplicações à aquisição/ aprendizagem e ao ensino da pronúncia de linguas estrangeiras. Anais IV congresso Brasileiro de Linguística Aplicada. p. 495-501, 1995.

BERQUIST, B. Memory models applied to L2 comprehension: a search for common ground. In: TAILLEFER, G.; PUGH, A. K. (Ed.). Lectire à l'Université: Langues maternelle, seconde et étrangère. Reading in the University: First, second and foreign languages. Toulouse: Presses de l'Université des Sciences Sociales de Toulouse, p.29-44, 1997.

BROOKSHIRE, R. H.; NICHOLAS, L. E. Comprehension of directly stated main ideas and details in discourse by brain-damaged and non-braindamaged listeners. Brain and Language, v. 21, p. 21-36, 1984.

BYGATE, M. Speaking. In: The Cambridge Guide to Teaching English to Speakers of Other Languages, p. 14-20. Ed. Carter, R. \& Nunan, D. Chapter 2. Cambridge: Cambridge University Press, 2001.

BYGATE, M. Effects of task repetition on the structure and control of oral language. In: BYGATE, M.; SKEHAN, P.; SWAIN, M. (Ed.). Researching Pedagogic Tasks Second Language Learning, Teaching and Testing. Applied Linguistics and Language Study. London: Longman, 2001b.

CANTOR, J.; ENGLE, R. W. Working memory capacity as long-term memory activation: an individual differences approach. Journal of Experimental Psychology: Learning, Memory, and Cognition, v. 5, p. 1101-1114, 1993.

CAPLAN, D. Language. Structure, processing, and disorders. Cambridge: MIT Press, 1992.

COWAN, N. Attention and memory: an integrated framework. Oxford: Oxford University Press, 1995.

CROOKES, G. Planning and interlanguage variation. Studies in second language Acquisition, v. 11, p. 367-383, 1989. 
CRYSTAL, D. The Cambridge Encyclopedia of the English Language. Cambridge University Press, 1995.

DANEMAN, M.; CARPENTER, P. A. Individual differences in working memory and reading. Journal of verbal learning and verbal behavior, v. 19, p. 450466, 1980.

ELLIS, N. C.; SINCLAIR, S. G. Working memory in the acquisition of vocabulary and syntax: putting language in good order. The quarterly journal of experimental psychology, 49A (1), p. 234-250, 1996.

ELLIS, R. Interlanguage variability in narrative discourse: Style shifting in the use of the past tense. Studies in Second Language Acquisition, v. 9, p. 12-20, 1987.

ELLIS, R. Task-based language learning and teaching. Oxford: Oxford University Press, 2003.

ENGLE, R. W.; ORANSKY, N. The evolution from short-term to working memory: multi-store to dynamic models of temporary storage. In: STERNBERG, R. J. (Ed.). The nature of cognition. Cambridge, MA: MIT Press, 1997. p. 515-555.

ENGle, R. W.; LAUGHLin, J. E.; TUHOLSKI, S. W.; CONWAY, A. R. A. Working memory, short-term memory and general fluid intelligence: A latent variable approach. Journal of Experimental Psychology: Genera, 1999.

ENGLE, R. W.; KANE, M. J.; TUHOLSKI, S. W. Individual differences in working memory capacity and what they tell us about controlled attention, general fluid intelligence and functions of the prefrontal cortex. In: MIYAKE, A.; SHAH, P. (Ed.). Models of working memory: mechanisms of active maintenance and executive control. New York: Cambridge University Press, 1999. p. 102-134.

ENGLE, R. W.; CANTOR, J.; CARULLO, J. J. Individual differences in working memory and comprehension: a test of four hypotheses. Journal of Experimental Psychology: Learning, Memory and Cognition, v. 18, p. 972992, 1992.

ESCUDERO, P. The perception of English vowel contrasts: Acoustic cue reliance in the development of new contrasts. In: JAMES, A.; LEATHER (Ed.). New Sounds 2000: Preceedings of the Fourth International Symposium of the Acquisition of Second-Language Speech (University of Amsterdam, September 2000). Klagenfurt: University of Klagenfurt, 2002. p. 122-131. 
FORTKAMP, M. B. M. Working memory capacity and L2 speech production: an exploratory study. 2000. Tese (Doutorado em Inglês e Literatura Correspondente) - UFSC, Florianópolis.

FOSTER, P.; SKEHAN, P. The influence of planning and task type on second language performance. Studies in Second language acquisition, v. 18, p. 299323, 1996.

FOSTER, P. Rules and Routines: A consideration of their role in the task-based language production of native and non-native speakers. In: BYGATE, M.; SKEHAN, P.; SWAIN, M. (Ed.). Researching pedagogic tasks - Second Language Learning and Testing. Longman, 2001.

FREED, B. F. What makes us think that students who study abroad become fluent? In: FREED, F. B. (Ed.). Second Language Acquisition in a Study Abroad Context. Philadelphia: John Benjamins North America, 1995.

GREEN, D. W. Control, activation, and resource: A framework and a model for the control of speech in Bilinguals. Brain and language, v. 27, p. 210223. Academic Press, 1986.

HARRINGTON, M. Working memory capacity as a constraint on L2 development. In: HARRIS, R. J. (Ed.). Cognitive processing in bilinguals. Amsterdam: Elsevier, 1992.

HARRINGTON, M.; SAWYER, M. L2 working memory capacity and L2 reading skill. Studies in Second Language Acquisition, v. 14, p. 25-38, 1993.

HEWINGS, M. Pronunciation Tasks. Cambridge University Press, 1993.

HUBER, W. Text comprehension and production in aphasia: Analysis in terms of micro and macroprocessing. In: JOANETTE, Y.; BROWNELL, H. H. (Ed.). Discourse ability and brain damage: Theoretical and empirical perspectives. Chestnut Hill, MA: Springer-Verlag, 1990.

ILLES, J.; FRANCIS, W. S.; DESMOND, J. E.; GABRIELI, J. D. E.; GLOVER, G. H.; POLDRACK, R.; LEE, C. J.; WAGNER, A. D. Convergent cortical representation of semantic processing in bilinguals. Brain and Language, v. 70, p. 347-363, 1999.

JUST, M. A.; CARPENTER, P. A. A theory of reading: from eye fixations to comprehension. Psychological Review, v. 87, p. 329-354, 1980.

JUST, M.; CARPENTER, P. The Psychology of Reading and Language Comprebension. Massachusetts: Library of Congress Cataloging-inPublication data, 1987. 
JUST, M. A.; CARPENTER, P. A. A capacity theory of comprehension: Individual differences in working memory. Psychological Review, v. 99, p. 122-149, 1992.

KINTSCH, W.; VAN DIJK, T. Toward a model of text comprehension and production. Psychological Review, v. 85, n. 5, p. 363-394, 1978.

LAPOINT, L. Neurogenic Disorders of Communication. In: MINIFIO, F. (Ed.). Introduction to Communication Sciences and Disorders. San Diego: Singular, 1994. p. 351-397.

LENNON, P. Investigating Fluency in EFL: A Quantitative Approach. Language Learning, v. 40, n. 3, p. 387-417, 1999.

LEVELT, W. J. M. Speaking: From intention to articulation. Cambridge, Massachusetts: The MIT Press. 1981. Chapters 1-2.

MEHNERT, $\mathrm{U}$. The effects of different lengths of time for planning on second language performance. Studies in Second Language Acquisition, v. 20, p. 83108, 1998.

MIYAKE, A.; FRIEDMAN, N. P. Individual differences in second language proficiency: working memory as language aptitude. In: HEALY, A. F.; BOURNE, Jr., L. E. (Ed.). Foreign language learning: Psycholinguistic studies on training and retention. Mahawah, N. J: Lawrence Erbaum, 1998. p. 339364 .

OBLER, L.; GJERLOW, K. Language and the brain. Cambridge: Cambridge University Press, 1999.

ORTEGA, L. Planning and focus on form in L2 oral performance. Studies in Second Language Acquisition, v. 21, p. 109-148, 1999.

PARADIS, M. Differential Use of Cerebral Mechanisms in Bilinguals. In: BANICH, Marie T.; MACK, Molly (Ed.). Mind, Brain, and Language. Mahwah: LEA, 2003.

PAWLEY, A.; SYDER, F. H. Two puzzles for linguistic theory: nativelike selection and nativelike fluency. In: RICHARDS, J. C.; SCHMIDT, R. W. (Ed.). Language and Communication, New York: Longman, 1983. p. 191-226.

PERFETTI, C. A.; LESGOLD, A. M. Discourse comprehension and sources of individual differences. In: JUST, M. A.; CARPENTER, P. A. (Ed.). Cognitive processes in comprehension. Hillsdale, NJ: Lawrence Erlbaum Associates, 1977. 
PHELPS, E. A. Brain versus behavioral studies of cognition. In: STERNBERG, R. J. (Ed.). The nature of cognition. Cambridge, MA: The MIT Press, 1999.

RIGGENBACH, H. Toward an Understanding of Fluency: a Microanalysis of Nonnative Speaker Conversations. Discourse Processes, v. 14, p. 423-441, 1991.

SCHMIDT, R. The role of consciousness in second language learning. Applied Linguistics, v. 11, p.17-46, 1990.

SIRIGU, A.; COHEN, I.; ZALLA, T.; PRADAT-DIEHL, P.; VAN EECKHOUT, P.; GRAFMAN, J.; AGID, V. Distinct frontal regions for processing sentence syntax and story grammar. Cortex, v. 14, p. 771-778, 1998.

SKEHAN, P.; FOSTER, P. Task type and task processing as influences on foreign language performance. In: SKEHAN, P. (Ed). Working papers in English Language Teaching, 3, 1995. p. 139-188.

SKEHAN, P. A Cognitive Approach to Language Learning. Oxford: Oxford University Press, 1998.

SKEHAN, P. A Framework for the Implementation of Task-based Instruction. Applied Linguistics, v. 17, n. 1. Oxford University Press, 1996.

SKEHAN, P.; FOSTER, P. Task type and task processing as influences on foreign language performance. In: SKEHAN, P. (Ed.). Working papers in English Language, 1995.

SPRINGER, S. P.; DEUTSCH, G. Left brain, right brain: Perspectives from neuroscience. New York: W.H. Freeman and Company, 1998. Chs. 1, p. 929, and 7, p.160-198.

TEMPLE, L. Disfluencies in Learning Speech. In Learner Speech. Australian Review of Applied Linguistics, v. 15, n.2, p. 29-44, 1992.

TOMITCH, L. M. B. Reading: Text organization perception and working memory capacity. Unpublished doctoral dissertation, Universidade Federal de Santa Catarina, Florianópolis, 1995.

TOMITCH, L. M. B. Individual Differences in the Text Organization Perception and Working Memory Capacity. Revista da ANPOLL, n. 2, p. 7193, 1996. 